\title{
Olive Oil/Soya Oil/Egg Lecithin-based Emulsion
}

National Cancer Institute

\section{Source}

National Cancer Institute. Olive Oil/Soya Oil/Egg Lecithin-based Emulsion. NCI Thesaurus. Code C111896.

An injectable, isotonic, nutritional lipid emulsion composed of approximately $80 \%$ refined olive oil and $20 \%$ refined soybean oil, used for parenteral nutrition. The olive oil/soya oil/egg lecithin emulsion provides about $15 \%$ of saturated fatty acids (SFA), $65 \%$ of mono-unsaturated fatty acids (MUFA) and $20 \%$ of essential poly-unsaturated fatty acids (EPUFA). Upon parenteral administration, the emulsion supplies calories, for energy, and essential fatty acids that can be incorporated into cell membranes. The fatty acids may decrease the production of certain pro-inflammatory cytokines, including interleukin 1 (IL1), IL-6 and tumor necrosis factor (TNF). In addition to olive oil and soya oil, this lipid emulsion contains egg lecithin and provides phosphorus and choline, which are needed to maintain cell membrane integ rity. 